\section{Maternidade e paternidade na adolescência: algumas constatações em três cidades do Brasil}

\author{
Teenage motherhood and fatherhood: \\ observations in three cities of Brazil
}

\author{
1 Instituto de Saúde Coletiva, \\ Universidade Federal \\ da Bahia, Salvador, Brasil. \\ 2 Universidade Estadual \\ de Feira de Santana, \\ Feira de Santana, Brasil. \\ Correspondência \\ A. B. Dias \\ MUSA - Programa Integrado \\ de Pesquisa e Cooperação \\ Técnica em Gênero e Saúde, \\ Instituto de Saúde \\ Coletiva, Universidade \\ Federal da Bahia. \\ Rua Basílio da Gama s/n, \\ Campus Universitário \\ do Canela, Salvador, BA \\ 40110-170, Brasil. \\ musa@ufba.br \\ acaciabatista@uol.com.br
}

\section{Abstract}

This study describes young people from 18 to 24 years of age who experienced motherhood and fatherhood. The data are from a multi-center study (the GRAVAD Research Project) conducted in the Brazilian cities of Porto Alegre, Rio de Janeiro, and Salvador through a household survey with a three-stage stratified probabilistic sample. Among a total of 4,634 interviewees, $17.9 \%$ of women and $6.3 \%$ of men became parents before the age of 20. Young fathers and mothers show low schooling and early participation in the work market. Most report a per capita monthly family income of some U\$150. The existence of children motivates the marital union at a young age, during which the roles of male provider and female caregiver are reaffirmed. Even for young parents who have formed a new family nucleus themselves, their own original families provide a basis of material and affective support.

Pregnancy in Adolescence; Gender Identity; Adolescent; Paternity
Acácia Batista Dias 1,2

Estela M. L. Aquino ${ }^{1}$

\section{Introdução}

Maternidade na adolescência é um tema que vem suscitando não só o interesse entre estudiosos da demografia, da saúde pública e das ciências sociais, como também o debate público. Os estudos demográficos têm demonstrado que no Brasil, nos últimos vinte anos, houve um aumento da taxa específica de fecundidade e uma elevação relativa de nascimentos em mulheres de 15 a 19 anos, em contraste com a tendência revelada em outros grupos etários, fato este também observado em alguns países da América Latina 1, e que reforça o argumento da gravidez na adolescência como "problema social". No campo da saúde, as questões debatidas relativas a essa temática enfatizam os riscos para a saúde das mães e das crianças provenientes de gestação em mulheres muito jovens 2,3,4. O enfoque de "risco" é ressaltado e associado a um imaginário contemporâneo que concebe a adolescência como um período de instabilidade, caracterizado por crises 5 . Também é comum aludir o comportamento juvenil a atitudes "descompromissadas" e a um estilo de vida efêmero, o que contribui para uma construção negativa dessa fase da vida 6 .

A compreensão do fenômeno da gravidez na adolescência com base numa perspectiva sociológica requer a identificação das condições sociais e históricas que deram a essa gravidez o estatuto de "problema". Significa enten- 
dê-lo por intermédio da ótica dos atores envolvidos, observando as suas posições e inserções sociais, empreendendo a relativização das formulações recorrentes 7. Uma cuidadosa revisão da literatura sobre a gravidez na adolescência elaborada por Brandão 8 identifica diferentes argumentos na abordagem da questão: a já mencionada situação de risco da gravidez precoce (e conseqüências), a incapacidade psíquica dos jovens para criar os filhos, o nexo com situações de marginalidade social e econômica, como também, as estratégias de inserção social e/ou no mundo dos adultos. Para essa autora, a literatura apresenta uma leitura social do fenômeno, ainda que esta não seja até o momento suficiente na explicação do sistema de representações e práticas presentes entre os jovens e que regulam suas trajetórias de vida.

Entretanto, tendo em vista que o evento da gravidez pressupõe envolvimento entre parceiros, mesmo se tratando de uma relação eventual, chama a atenção o fato de que a literatura sobre o tema não contemple os homens, circunscrevendo a questão ao universo feminino $5,6,9,10$. No Brasil, uma parte dos estudos sobre maternidade na adolescência define como objeto de investigação a população de jovens grávidas que freqüenta serviços de saúde, sendo em menor número os estudos populacionais $\mathrm{e}$ aqueles que incorporam a perspectiva masculina e as circunstâncias familiares em que o fenômeno está inserido.

O contexto social no qual ocorre a maternidade/paternidade na adolescência e os principais desdobramentos na vida desses jovens advindos do nascimento da criança são questões fundamentais na análise da experiência de parentalidade juvenil. Assim, interessa saber: o que muda e o que permanece na biografia desses sujeitos? O que há de específico na condição de jovens pais/mães? Tais indagações possibilitam, em especial, a visibilidade da situação dos rapazes nesse processo, haja vista a centralidade de referências que identificam as esferas doméstica e familiar como domínio feminino. Muitos estudos ainda reafirmam a associação mulher-mãe "naturalizando" a sua relação com os filhos.

Recentemente, pode-se observar a construção de perspectivas analíticas que contemplam as novas configurações familiares e os novos posicionamentos dos indivíduos, sugerindo mudanças de comportamentos nos relacionamentos entre seus membros. A maternidade como fenômeno social é marcada por desigualdades sociais, raciais/étnicas e de gênero ${ }^{11}$. É ainda sobre a mulher que recaem as principais atribuições e responsabilidades com os filhos, sendo comum nas relações familiares, a constituição de uma rede feminina de solidariedade e apoio para cuidar das crianças 12. Embora tal prática não esteja circunscrita a um segmento social, ela é particularmente importante entre as pessoas das camadas populares. $\mathrm{Na}$ sociedade brasileira, a contribuição familiar se expressa de forma diversificada e fundamental para a sobrevivência dos membros do grupo, tendo em vista o pouco investimento em prestação e assistência sociais pelo setor público, sobretudo quando comparado a países como a França 13. Dessa forma, nos dados aqui analisados, verifica-se que no caso de pais e mães na adolescência, os adultos, especialmente os/as avós das crianças, estão sempre envolvidos no sustento e cuidado de seus netos.

A juventude é caracterizada por um processo de transição para a vida adulta e nesse percurso as mudanças ocorridas são consubstanciadas por condições sociais muito distintas, como gênero e classe social. É próprio da contemporaneidade que essa passagem seja marcada por uma multiplicidade de situações expressa nas "primeiras vezes" em que o/a jovem realiza uma nova experiência 14,15 , entre as quais se destacam: a iniciação sexual, a primeira gravidez e o primeiro filho. A situação de parentalidade na adolescência revela uma diversidade de razões, causas, motivações e perfis desses sujeitos, retratando uma peculiar heterogeneidade.

O presente estudo insere-se na Pesquisa GRAVAD - Gravidez na Adolescência: Estudo Multicêntrico sobre Jovens, Sexualidade e Reprodução no Brasil-, que utilizou duas estratégias metodológicas de produção de dados: uma qualitativa e outra quantitativa. Com base nos dados advindos dessa última estratégia, busca-se caracterizar os jovens que se tornaram mães e pais na adolescência, mediante variáveis sócio-demográficas, ressaltando os desdobramentos motivados pelo nascimento do primeiro filho nas suas trajetórias biográficas, assim como os apoios familiares estabelecidos para o cuidado da criança.

\section{Aspectos metodológicos}

A Pesquisa GRAVAD foi desenvolvida nas cidades de Salvador, Rio de Janeiro e Porto Alegre, Brasil. A etapa quantitativa realizou-se por meio de um inquérito domiciliar, com entrevistas face a face, entre os meses de outubro de 2001 e janeiro de 2002. Foi utilizada uma amostragem probabilística de residentes de ambos os sexos, nas três cidades, com idade de 18 a 24 anos, es- 
tratificada em três estágios. No primeiro momento, em cada cidade, os setores censitários unidades primárias de amostragem, que constituem unidades operacionais básicas definidas pelo Instituto Brasileiro de Geografia e Estatística (IBGE) para a realização dos censos demográficos - foram agrupados em cinco estratos, de acordo com a renda média e a escolaridade do chefe do domicílio. A constituição da amostra de setores censitários foi feita independentemente em cada estrato, pela seleção aleatória de setores, proporcional ao número de jovens de 18 a 24 anos em cada setor. Em seguida, foi realizada uma listagem dos domicílios particulares permanentes, destacando-se aqueles em que havia moradores na faixa etária de interesse, completados na data de referência da pesquisa (31 de julho de 2001), e sorteados 33 domicílios com eqüiprobabilidade e sem reposição. Finalmente, em cada um dos domicílios, foi escolhido aleatoriamente um/a jovem para a entrevista 16.

A estimativa do número total de jovens a serem entrevistados foi de 4.500 (1.500 em cada município), considerando como parâmetro os dados da Pesquisa Nacional sobre Demografia e Saúde 17, que revelava em 1996, que 25,3\% das mulheres brasileiras de 18 anos já haviam experimentado pelo menos um episódio de gravidez.

O recorte etário da população alvo, ao não se situar dentro dos limites estabelecidos pela Organização Mundial da Saúde (OMS) como adolescência 18, definida na faixa etária de 10 a 19 anos, busca obter dados sobre os eventos acontecidos numa fase de vida imediatamente subseqüente, possibilitando a reconstrução retrospectiva de tais eventos. Assim, além de indivíduos de 18 e 19 anos, considerados adolescentes, foram também contemplados jovens nas faixas etárias de 20 a 24 anos, de modo a analisar o impacto da gravidez na adolescência nas suas vidas. Dessa forma, também, evitavam-se os problemas operacionais da exigência de consentimento parental para participação na pesquisa. Contudo, para fins analíticos considerou-se como maternidade e paternidade na adolescência aquela em que o filho nasceu antes do/a jovem ter completado vinte anos.

As entrevistas foram realizadas por jovens homens e mulheres com nível superior completo ou incompleto, prevalecendo a formação em Ciências Humanas, e treinados para este fim. Os dados foram processados com a utilização dos programas Epi Info versão 6.04b (Centers for Disease Control and Prevention, Atlanta, Estados Unidos) para constituição da base de dados e do Stata versão 8 (Stata Corpo- ration, College Station, Estados Unidos) para análises estatísticas, permitindo a incorporação do efeito do desenho amostral e dos pesos relativos a cada unidade, favorecendo a obtenção de estimativas com parâmetros confiáveis. A fim de avaliar a ocorrência da parentalidade na adolescência, calculou-se a proporção de pelo menos um filho nascido antes dos vinte anos e seu devido intervalo de confiança de 95\% (IC95\%). Na análise dos dados, procedeuse à distribuição de freqüências simples e cruzamentos para a caracterização da população investigada. As diferenças entre os percentuais foram testadas quanto à significância estatística pelo uso do $\chi^{2}$ de Pearson.

A Pesquisa GRAVAD teve aprovação nos Comitês de Ética de todas as instituições envolvidas. Foi utilizado também um Termo de Consentimento Livre e Esclarecido que era lido antes de começar a entrevista e assinado ao final. Esse documento explicitava os objetivos da investigação, assegurava a confidencialidade da informação, o direito de não responder determinada questão ou interromper a entrevista a qualquer momento 19.

\section{O que os dados revelam}

\section{Experiência de maternidade e paternidade na adolescência}

Do total de 4.634 pessoas entrevistadas nas três cidades, 17,9\% de mulheres (IC95\%: 15,8-20,2) e 6,3\% de homens (IC95\%: 4,7-8,4) tiveram experiência de maternidade e paternidade antes dos vinte anos (dados não apresentados). Nos dados da pesquisa são observadas algumas especificidades acerca do comportamento sexual dos/as jovens na comparação nas três cidades. Desse modo, verifica-se que as moças de Porto Alegre se iniciam sexualmente mais cedo e têm menor ocorrência de gravidez em oposição a Salvador, onde as jovens possuem iniciação mais tardia, maior ocorrência de gravidez, como também se previnem menos contra as doenças sexualmente transmissíveis e AIDS 16. O Rio de Janeiro ocupa uma posição intermediária entre as cidades citadas 16,19. Observa-se ainda que $74,3 \%$ das mulheres cuja primeira gravidez ocorreu antes dos vinte anos tiveram como resultado o nascimento de um filho, ao passo que entre os homens a proporção é de $36,6 \%$, na mesma circunstância 19 . Vale ressaltar que os parceiros dessas mulheres geralmente são mais velhos do que elas, situação que endossa as regras do mercado matrimonial, entre as quais se destaca a tendência das 
mulheres à composição de relações afetivo-sexuais com homens mais velhos 16 .

Pais e não-pais na adolescência: semelhanças e diferenças

Buscando-se evidenciar a diversidade de contextos em que os jovens experimentaram a paternidade/maternidade na adolescência, foi proposto um contraste de perfis com aqueles/as que não tiveram essa experiência. Inicialmente, observa-se que a maioria dos jovens pais / mães $(68,8 \%)$ declara renda mensal familiar per capita até um salário mínimo (dados não apresentados). É interessante perceber que no tocante ao nível de instrução as jovens mães apresentam menor escolaridade em relação às não-mães, fato que é semelhante para os rapazes (Tabela 1). O investimento na escolarização sugere um adiamento do exercício das funções parentais. Chama a atenção, além disso, o baixo percentual de jovens pais e mães que têm inserção universitária, inferior a 1,5\% em ambos os casos, quando comparados àqueles que não tiveram experiência de parentalidade na adolescência (Tabela 1).

Estudos sobre situação educacional juvenil comumente apontam a evasão escolar, feminina e masculina, correlacionada à condição de pai/mãe na adolescência, justificada pela necessidade de cuidado e do sustento do filho, particularmente quando acontece formação de novo grupo familiar 20. Entretanto, a associação entre a gravidez na adolescência e conseqüência na trajetória escolar adquire novos contornos quando se verifica, pela análise dos resultados do presente estudo, que são comuns situações de interrupção do projeto de escolarização anteriores à situação de gravidez 21 , sobretudo nas camadas populares, em que as próprias condições materiais de existência determinam restrições e impõem outras prioridades aos sujeitos (dados não apresentados). O nascimento da criança, muitas vezes, configura-se em mais um motivo de interrupção dos estudos dentro de um itinerário escolar já entrecortado. Os jovens pais e mães destacam-se nessa condição, sendo a diferença estatisticamente significante para ambos os sexos (Tabela 1).

Os entrevistados declaram razões diversas que propiciam suas entradas e saídas da escola. Fatores como o desinteresse pelo estudo, a inserção no trabalho e a estrutura do sistema educacional, principalmente na rede pública, contribuem para composição de um percurso fragmentado da vida escolar, tanto para mulheres como para homens. Começar a trabalhar e continuar estudando são, para alguns jovens, tarefas de difícil conciliação. A busca por rendimentos próprios é muitas vezes motivada, sobretudo no caso dos rapazes, em função dos anseios por um projeto de autonomia e expectativas de consumo que se viabilizam por intermédio do trabalho 22 . Dessa maneira se estabelece o vínculo com o espaço público, forma-se a identidade masculina e adquire-se reconhecimento no mundo adulto.

A entrada no mercado de trabalho difere entre os sexos dos entrevistados, sendo a proporção daqueles que começaram a exercer atividade remunerada antes dos 14 anos de $23,5 \%$ para os rapazes e de $13,1 \%$ para as moças, e a proporção dos que nunca trabalharam de 10,1\% e $20,6 \%$, respectivamente. Ao se considerar a condição de parentalidade na adolescência, por sexo, observa-se que jovens mães e pais começam a trabalhar mais precocemente em relação aos que não tiveram filhos nessa etapa da vida (Tabela 1).

No momento da entrevista, a maioria dos homens declara estar trabalhando, sendo maior o percentual de jovens pais $(72,9 \%)$ nesta condição. Possivelmente, a presença do filho e a responsabilidade de provê-lo reafirmam a relação social que vincula trabalho e identidade masculina 23. Entre as mulheres a situação se inverte, sendo a condição de não trabalho maior para as jovens mães (Tabela 1). As funções da maternidade e a responsabilidade com o serviço doméstico costumam ser apontadas, pelas mulheres, como atenuantes para postergar a inserção ou promover o afastamento do trabalho 24 .

Em termos de situação de residência, mais de $70 \%$ dos entrevistados de ambos os sexos e sem experiência de parentalidade na adolescência, declaram morar atualmente com a família de origem: ambos os pais ou pelo menos um deles, sendo a diferença estatisticamente significante quando comparados aos jovens pais e mães (Tabela 1). Vale ressaltar que cerca de metade dos últimos vive em domicílio sem a presença de pais ou responsáveis, o que se aproxima da proporção de união conjugal deste grupo, bastante superior à encontrada entre aqueles que não tiveram experiência de maternidade/paternidade na adolescência. Desse modo, a existência de filhos parece motivar a conjugalidade de homens e mulheres, sem que, no entanto, a formação de uma união signifique necessariamente uma autonomia do novo casal frente às famílias de origem. Comumente, jovens unidos conjugalmente, residindo ou não com seus pais, mantêm uma relação de dependência afetiva e material quer seja da família de origem, quer seja da família do/a parcei- 
Distribuição de jovens na condição de mães/pais e não mães/não pais na adolescência segundo características sócio-demográficas por sexo. População de jovens de 18 a 24 anos de Porto Alegre, Rio de Janeiro e Salvador, Brasil.

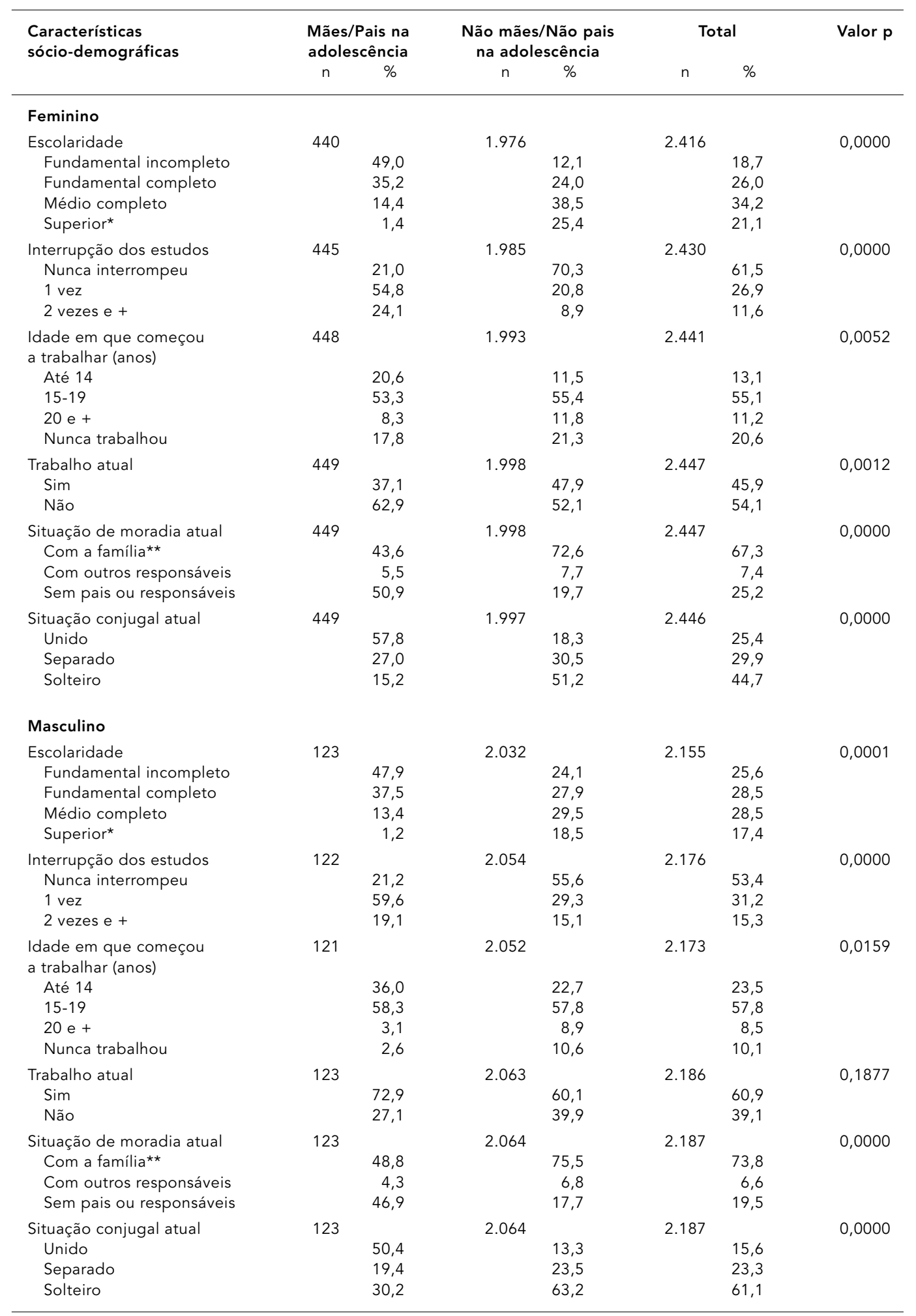

* Curso completo ou incompleto;

** Inclui ambos os pais ou apenas um deles.

Fonte: Pesquisa Gravad, 2002. 
ro/a; em alguns casos, de ambas, especialmente nas questões de cuidado com a criança e contribuição financeira 24 .

\section{Contexto familiar}

A discussão sobre experiência de maternidade e paternidade na adolescência suscita indagações a respeito de determinados condicionantes familiares. Para fins deste estudo foi possível mapear algumas situações vividas por estes jovens, entre os 15 e 18 anos, e a história familiar reprodutiva e tamanho da família. A maioria dos jovens de ambos os sexos, naquela idade, residia com ambos os pais ou apenas com um deles. Nessa última situação destacam-se os arranjos familiares do tipo monoparental feminino, cuja proporção é superior a $20 \%$ (Tabela 2). Segundo estudos demográficos realizados no Brasil, há um aumento desse tipo de arranjo familiar, juntamente com condições de maior precariedade de capital econômico e cultural a ele associado 25 .

Chama a atenção o fato de que, nessa idade, 21,9\% das jovens mães já residiam com seus parceiros (Tabela 2). Esse dado tem consonância na ressalva feita anteriormente a respeito do relacionamento afetivo-sexual de moças com parceiros mais velhos, o que, em muitos casos, significa que eles possuem posição e inserção social diferente da maioria dos adolescentes, viabilizando, assim, a união conjugal 24. Segundo dados do último Censo Demográfico 26, o número de mulheres brasileiras, entre 15 a 19 anos, já unidas conjugalmente é três vezes maior do que os homens nessa mesma faixa etária. No presente estudo, verifica-se que, na faixa etária de 15 a 18 anos, os jovens pais apresentam baixos percentuais de união, e é raríssima a condição de rapazes sem experiência de paternidade em estado conjugal. Situação semelhante é verificada entre as moças que não foram mães na adolescência (Tabela 2).

Quanto à participação dos/as jovens nas tarefas domésticas, fica evidente uma lógica de gênero. De um modo geral, as mulheres declaram maior inserção nessas atividades em relação aos homens, cuja participação é bastante diferente, sendo expressivos entre eles os percentuais de "ajuda" e "não ter obrigação" (Tabela 2). Para as moças, em especial das camadas populares, a realização desse tipo de atividade na casa dos pais (incluindo o cuidado com os irmãos menores) se configura como uma socialização para uma futura inserção profissional delas 24 , haja vista que o trabalho doméstico é sempre mencionado pelas moças como atividade que propicia rendimentos. Entre as en- trevistadas, existe uma maior participação nas tarefas domésticas quando houve experiência de maternidade na adolescência.

Um dos argumentos recorrentes na literatura sobre gravidez na adolescência é o de que os filhos tendem a repetir a história reprodutiva de sua família 27. Na Pesquisa GRAVAD, 52,5\% das jovens mães declaram que suas próprias mães tiveram o primeiro filho também antes dos vinte anos de idade, enquanto, ao contrário, a maioria das jovens não-mães $(67,8 \%)$ afirmou que suas respectivas mães experimentaram a maternidade após esta faixa etária. No caso dos homens, as diferenças não são significantes (Tabela 2). A ocorrência de parentalidade na adolescência é também mais freqüente entre aqueles/as que tiveram irmãos com essa experiência. Aqui são as jovens mães que apresentam maior analogia com suas mães quanto à ocorrência de filho antes dos vinte anos de idade, o que possibilita inferir acerca de uma simetria de gênero.

A existência de um maior número de irmãos é representativa no grupo de pais e mães juvenis: em torno de $40 \%$ deles possuem de três a cinco irmãos (Tabela 2). Situação oposta aos entrevistados sem experiência de parentalidade na adolescência, em que a maioria declara o máximo de dois irmãos.

\section{Desdobramentos na biografia dos jovens a partir do nascimento de um filho}

Considera-se que o nascimento de um filho na adolescência representa uma etapa de transição para a vida adulta 5,7,19. Essa passagem, que possui marcas diferenciadas pela posição social dos indivíduos, revela significados próprios para pais e mães, demarcados por relações de gênero e expressos nos desdobramentos ocasionados pela existência de um filho numa etapa de vida determinada.

Os dados analisados revelam que a presença do filho motiva a união dos pais: $31,3 \%$ das jovens mães se uniram após o nascimento do mesmo, embora $21,8 \%$ delas já fossem unidas quando tiveram seus bebês. A proporção de união conjugal em razão da presença do filho é mais expressiva para os homens, sobretudo quando comparados os casos de união prévia. Porém, o percentual de entrevistados de ambos os sexos que permaneceu com a família de origem é significativo (Figura 1), situação que pode ser compreendida se forem consideradas a idade dos jovens pais/mães, as condições sócioeconômicas e, sobretudo no caso das mulheres, a possibilidade de a família assegurar maior proteção e cuidado com a moça e seu filho. 
Distribuição de mães/pais e não mães/não pais na adolescência segundo características familiares e de socialização por sexo. População de jovens de 18 a 24 anos de Porto Alegre, Rio de Janeiro e Salvador, Brasil.

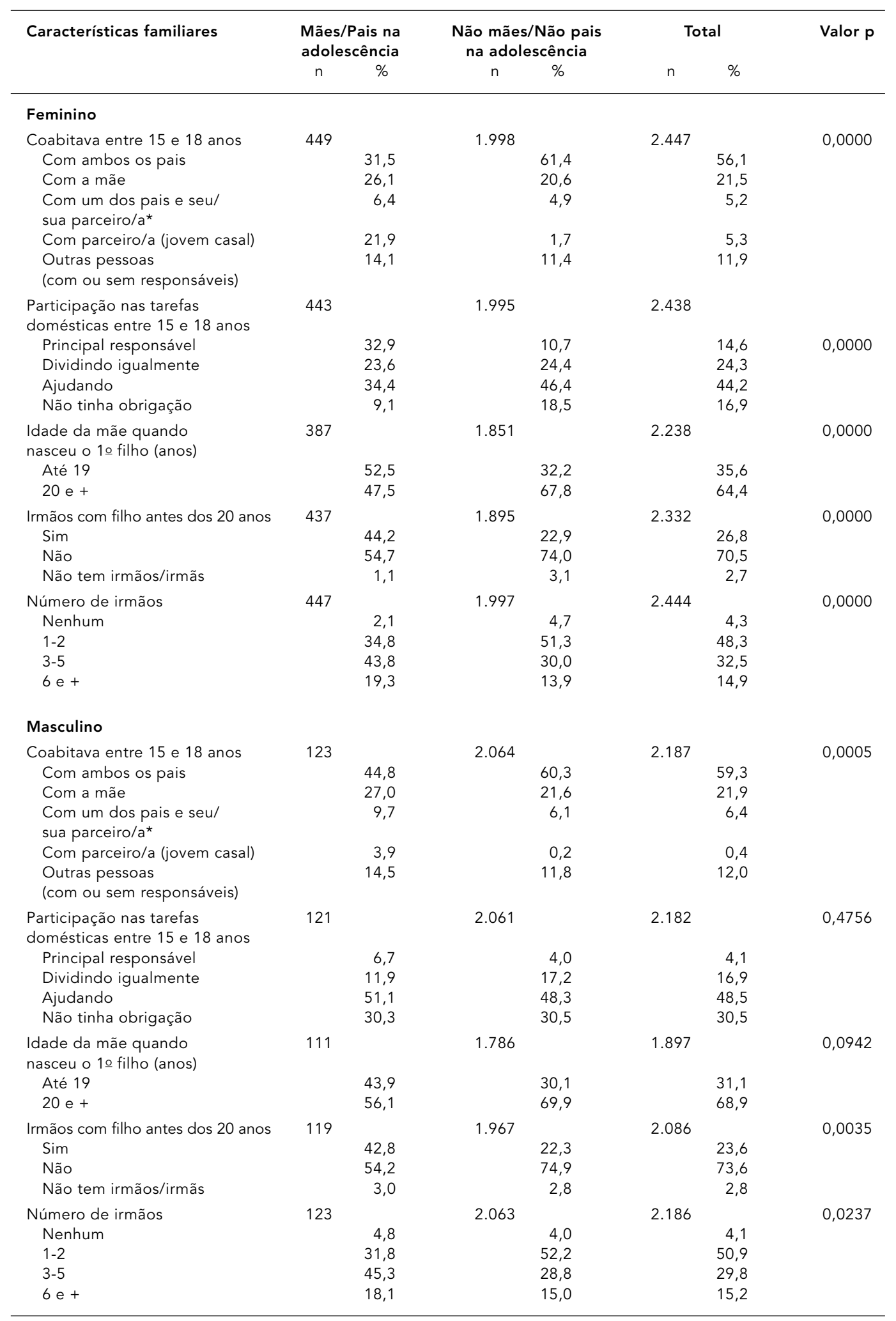

* Referência à parceria dos pais/mães dos jovens.

Fonte: Pesquisa GRAVAD, 2002. 
Distribuição de jovens de 18 a 24 anos que foram mães/pais na adolescência segundo situação de moradia até um ano após o nascimento do primeiro filho por sexo. Porto Alegre, Rio de Janeiro e Salvador, Brasil.

1a) Mulheres $(n=448)$

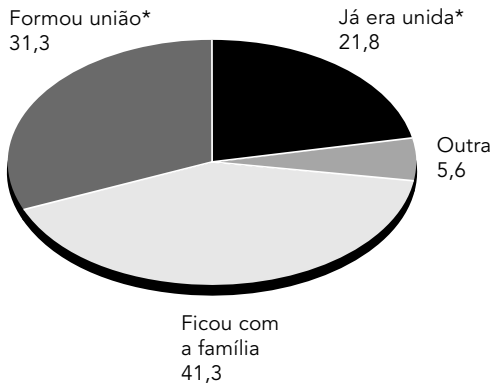

1b) Homens ( $n=122)$

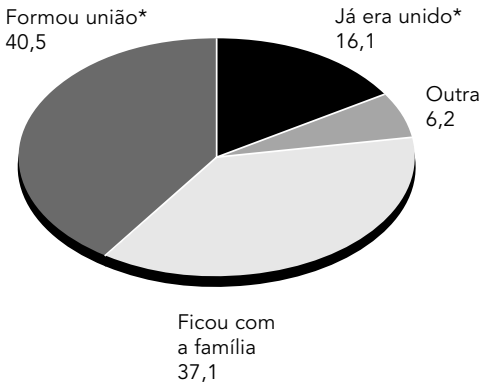

* Com ou sem família.

$\mathrm{p}=0,6825$.

Fonte: Pesquisa GRAVAD, 2002.

Quanto à trajetória escolar, encontra-se um alto percentual de homens e mulheres, $(47,8 \%$ e 40,2\%, respectivamente) que já estavam fora do sistema de ensino quando nasceu o primeiro filho (dados não apresentados). Mas são as moças que mais interrompem os estudos nessa fase em que o bebê demanda cuidados. A evidência de que são as adolescentes que sofrem maior impacto sobre o percurso escolar já foi referida em outros estudos 1,16 , ao passo que o percentual de rapazes que continuam estudando é duas vezes maior do que o de mulheres 19. Em termos de trabalho, a situação é semelhante à descrita anteriormente, as jovens mães já se encontravam fora do mercado e os jovens pais continuaram trabalhando. A diminuição do convívio com amigos, à época do nascimento do primeiro filho, é mais mencionada pelas mulheres. São elas que se ressentem mais pela restrição da vida social, especialmente nos primeiros meses de vida do bebê 8,24 . A diferença entre rapazes e moças revela a reprodução da assimetria de gênero: tornar-se mãe parece estreitar os laços entre a condição de ser mulher e o espaço privado 19.

\section{Situação atual do primeiro filho}

A análise das condições atuais do primeiro filho tem como referência a situação conjugal dos entrevistados. Destaca-se que a maioria dos casais é formada pelos pais das crianças $(71,9 \%$ das mulheres e $60,5 \%$ dos homens). Em contra- partida, quando os pais não estão unidos conjugalmente prevalece a moradia da criança com sua mãe e a família materna (Tabela 3 ).

Rapazes e moças em união conjugal apontam o pai como principal responsável pelo sustento da criança. Esse é um aspecto carregado de significados morais para os homens, pois, em última instância, a possibilidade de prover os filhos, compõe, em grande medida, a identidade masculina 22. Entre as moças não unidas, verifica-se que recai sobre elas e seus pais a responsabilidade com as despesas do filho/neto (Tabela 3).

Cuidar de filho continua socialmente sendo uma questão feminina, permanecendo uma naturalização da maternidade e um estranhamento da paternidade, mormente quando se trata de questões como tutela, cuidado e educação. No entanto, alguns autores afirmam um crescimento do envolvimento de homens com as atividades domésticas, especialmente nas tarefas de cuidado com a criança, o que vem sendo denominado de "nova paternidade" 28.

Independentemente do tipo de arranjo familiar em que a criança está inserida, é alta a proporção de mães que toma conta do filho. Todavia, entre jovens unidos, é expressiva a participação do pai no cuidado com os filhos. Logo, a "nova paternidade", se não representa uma divisão sexual de trabalho mais igualitária em termos de responsabilidade com as crianças, já se anuncia como uma postura mais participativa dos pais, sobretudo entre os mais jo- 
Distribuição de jovens que foram mães e pais na adolescência segundo a situação atual do primeiro filho por situação conjugal e sexo. População de jovens de 18 a 24 anos de Porto Alegre, Rio de Janeiro e Salvador, Brasil.

\begin{tabular}{|c|c|c|c|c|c|}
\hline \multirow{3}{*}{ Situação atual do primeiro filho } & \multicolumn{4}{|c|}{ Situação conjugal } & \multirow[t]{3}{*}{ Valor $\mathrm{p}$} \\
\hline & \multicolumn{2}{|c|}{ Unido/a } & \multicolumn{2}{|c|}{ Não unido/a } & \\
\hline & $\mathrm{n}$ & $\%$ & $\mathrm{n}$ & $\%$ & \\
\hline \multicolumn{6}{|l|}{ Mulheres } \\
\hline Com quem vive & 278 & & 164 & & 0,0000 \\
\hline Com ambos os pais* & & 71,9 & & 3,4 & \\
\hline Só com a mãe & & 4,6 & & 18,2 & \\
\hline Com a mãe e familiares & & 8,5 & & 68,9 & \\
\hline Outros & & 15,0 & & 9,5 & \\
\hline Principal responsável pelo sustento da criança & 273 & & 162 & & 0,0000 \\
\hline Pai & & 54,7 & & 12,7 & \\
\hline Ambos os pais & & 20,6 & & 7,6 & \\
\hline Mãe & & 4,1 & & 23,2 & \\
\hline Avós maternos & & 8,0 & & 44,6 & \\
\hline Outros & & 12,5 & & 12,0 & \\
\hline \multicolumn{6}{|l|}{ Quem toma conta** } \\
\hline Mãe & 273 & 89,1 & 162 & 85,5 & 0,2804 \\
\hline Pai & 271 & 59,3 & 160 & 23,2 & 0,0000 \\
\hline Avós maternos & 271 & 45,2 & 161 & 82,1 & 0,0000 \\
\hline Avós paternos & 271 & 24,7 & 159 & 24,9 & 0,9716 \\
\hline Creche & 271 & 23,1 & 159 & 31,0 & 0,1254 \\
\hline Vizinhos & 269 & 13,3 & 158 & 21,8 & 0,1012 \\
\hline Empregada & 269 & 3,3 & 158 & 4,1 & 0,6868 \\
\hline \multicolumn{6}{|l|}{ Homens } \\
\hline Com quem vive & 51 & & 69 & & 0,0053 \\
\hline Com ambos os pais* & & 60,5 & & 7,2 & \\
\hline Só com a mãe & & 5,9 & & 17,8 & \\
\hline Com a mãe e familiares & & 26,4 & & 62,5 & \\
\hline Outros & & 7,1 & & 12,5 & \\
\hline Principal responsável pelo sustento da criança & 51 & & 69 & & 0,0763 \\
\hline Pai & & 55,7 & & 24,7 & \\
\hline Ambos os pais & & 14,2 & & 13,4 & \\
\hline Mãe & & 20,6 & & 15,9 & \\
\hline Avós maternos & & 3,7 & & 25,7 & \\
\hline Outros & & 5,9 & & 20,2 & \\
\hline \multicolumn{6}{|l|}{ Quem toma conta** } \\
\hline Mãe & 49 & 92,7 & 68 & 84,4 & 0,1768 \\
\hline Pai & 49 & 55,0 & 66 & 22,5 & 0,0399 \\
\hline Avós maternos & 46 & 50,5 & 66 & 78,1 & 0,0357 \\
\hline Avós paternos & 44 & 46,3 & 60 & 55,4 & 0,6073 \\
\hline Creche & 47 & 49,0 & 63 & 15,3 & 0,0080 \\
\hline Vizinhos & 45 & 6,1 & 63 & 3,0 & 0,4282 \\
\hline Empregada & 45 & - & 65 & 2,8 & - \\
\hline
\end{tabular}

* O caso dos jovens sem união inclui situações variadas entre guarda e moradia compartilhadas;

** Resposta múltipla.

Fonte: Pesquisa GRAVAD, 2002. 
vens. No entanto, ainda que essa contribuição se caracterize por diferentes formas de atuação em tempos e lugares demarcados por relações de gênero e classe social, é a coabitação do filho com o pai que potencializa a participação deste no seu cuidado, visto que entre os moças e rapazes não unidos a proporção de pais no cuidado dos filhos se reduz a cerca de $20 \%$ (Tabela 3).

Entretanto, a realização das atividades relacionadas ao cuidado infantil e as restrições sociais impostas pela maternidade compõem o cotidiano feminino. A participação dos avós maternos, tanto nos relatos das moças como dos rapazes, é sempre significativa, particularmente entre os/as jovens não unidos/as, caracterizando práticas familiares de suporte financeiro, auxílio e solidariedade de pais com seus filhos, cumprindo, assim, em relação aos netos, as funções parentais. Destacam-se, nesse processo, as avós que assumem as responsabilidades e os cuidados com a criança 29 , reafirmando, dessa forma, a centralidade da mulher nas relações familiares. A cooperação de avós paternos é menos declarada, sendo um pouco maior entre os rapazes sem união (Tabela 3 ).

\section{Considerações finais}

Neste estudo, foram constatadas algumas especificidades nas biografias dos jovens que tiveram experiência de parentalidade na adolescência, em comparação com aqueles que não vivenciaram essa experiência. Os jovens pais/ mães apresentam baixa escolaridade e inserção mais precoce no mercado de trabalho. No entanto, essa situação não aparece como conseqüência direta da gravidez na adolescência.
O percurso escolar desses jovens é marcado por interrupções do estudo que antecedem esse evento, assim como o início das atividades remuneradas. No campo das Ciências Sociais, percebe-se o fortalecimento do argumento da maternidade e paternidade juvenis como busca de reconhecimento e inserção sociais dos sujeitos, em que pese a heterogeneidade de situações que envolvam os jovens e as questões presentes na decisão de levar a gravidez a termo.

Compondo o quadro de referência da Pesquisa GRAVAD, vale ressaltar a visibilidade conferida à paternidade e a possibilidade de confrontar declarações masculinas e femininas. É perceptível uma maior participação do pai não circunscrita ao sustento do filho. No entanto, prevalece, ainda, a lógica de gênero que define o espaço doméstico, sobretudo, o cuidado com a criança, como domínio do feminino e a função de provedor associada ao masculino. A rede de solidariedade e cooperação que se estabelece para ajudar a adolescente mãe é composta, na sua maioria, por mulheres - destaque para a rede de parentesco.

A família se constitui em fonte de apoio material desses jovens pais/mães: independentemente do segmento social e da situação de coresidência, há sempre uma ajuda importante no sustento deles/as e suas crianças. As avós maternas estão sempre próximas aos netos, assumindo responsabilidade de cuidado com eles. A reflexão acerca da juventude e a condição de parentalidade suscitam a importância da compreensão da família como instância de interseção de apoio afetivo-material, que consubstancia o movimento de construção da autonomia e redimensiona a relação de dependência desses jovens.

\section{Resumo}

Este estudo descreve jovens de 18 a 24 anos que experimentaram a maternidade e a paternidade na adolescência. Os dados são oriundos de um estudo multicêntrico (Pesquisa GRAVAD) realizado nas cidades brasileiras de Porto Alegre, Rio de Janeiro e Salvador, por meio de inquérito domiciliar, com amostragem probabilística estratificada em três estágios. Do total de 4.634 pessoas entrevistadas, 17,9\% de mulheres e 6,3\% de homens tornaram-se pais antes dos vinte anos. Os jovens pais/mães apresentam baixa escolaridade $e$ inserção precoce no mercado de trabalho. A maioria des- ses jovens declara renda familiar per capita até um salário mínimo. A existência de filhos motiva a união conjugal juvenil, na qual se reafirmam as funções de prover e cuidar da criança para homens e mulheres, respectivamente. A família se constitui como instância fundamental de apoio material e afetivo para os jovens pais, mesmo para aqueles que formaram um novo grupo familiar.

Gravidez na Adolescência; Identidade de Gênero; Adolescente; Paternidade 


\section{Colaboradores}

A. B. Dias foi entrevistadora, participou da interpretação dos resultados e da redação do artigo. E. M. L. Aquino participou da concepção e coordenação do estudo em todas as suas etapas, incluindo análise dos dados e redação do artigo.

\section{Referências}

1. Gupta N, Leite IC. Adolescent fertility behavior: trends and determinants in Northeastern Brazil. Int Fam Plan Perspect 1999; 25:125-30.

2. Motta ML, Silva JLP. Gravidez entre adolescentes muito jovens. Femina 1996; 22:348-54.

3. Silva RS. Gravidez na adolescência: onde mora o problema? In: Anais do 10o Encontro Nacional de Estudos Populacionais. Belo Horizonte: Associação Brasileira de Estudos Populacionais; 1996. p. 1545-65.

4. Gama SG, Szwarcwald CL, Leal MC, Theme-Filha MM. Gravidez na adolescência como fator de risco para baixo peso ao nascer no Município do Rio de Janeiro, 1996 a 1998. Rev Saúde Pública 2001; 35:74-80.

5. Cabral CS. Vicissitudes da gravidez na adolescência entre jovens das camadas populares do Rio de Janeiro [Dissertação de Mestrado]. Rio de Janeiro: Instituto de Medicina Social, Universidade do Estado do Rio de Janeiro; 2002.

6. Medrado B, Lyra J. A adolescência "desprevenida" e a paternidade na adolescência: uma abordagem geracional e de gênero. In: Schor N, Mota MSFT, Castelo-Branco V, organizadores. Cadernos: Juventude, Saúde e Desenvolvimento. v. 1. Brasília: Ministério da Saúde; 1999. p. 230-48.

7. Heilborn ML, Salem T, Rohden F, Brandão E, Knauth D, Victora C, et al. Aproximações socioantropológicas sobre gravidez na adolescência. Horizontes Antropológicos 2002; 8:13-45.

\section{Agradecimentos}

A investigação Gravidez na Adolescência: Estudo Multicêntrico sobre Jovens, Sexualidade e Reprodução no Brasil (Pesquisa GRAVAD) foi elaborada por Maria Luiza Heilborn (Instituto de Medicina Social, Universidade do Estado do Rio de Janeiro - IMS/UERJ), Michel Bozon (Institute National d'Études Démographiques - INED, França), Estela M. L. Aquino (Programa Integrado de Pesquisa e Cooperação Técnica em Gênero e Saúde/Universidade Federal da Bahia MUSA/UFBA) e Daniela Knauth (Núcleo de Antropologia do Corpo e Saúde/Universidade Federal do Rio Grande do Sul - NUPACS/UFRGS). O estudo foi realizado por três centros: Programa em Gênero, Sexualidade e Saúde (IMS/UERJ), MUSA/UFBA e NUPACS/ UFRGS. Os principais resultados do inquérito encontram-se publicados no livro O Aprendizado da Sexualidade: Reprodução e Trajetórias Sociais de Jovens Brasileiros (Rio de Janeiro: Garamond; 2006), onde podem ser obtidas informações sobre a composição detalhada da equipe de pesquisadores. Agradecemos também à Fundação Ford, ao programa de bolsas do Conselho Nacional de Desenvolvimento Científico e Tecnológico e à Coordenação de Aperfeiçoamento de Pessoal de Nível Superior.

8. Brandão ER. Individualização e vínculo familiar em camadas médias: um olhar através da gravidez na adolescência [Tese de Doutorado]. Rio de Janeiro: Instituto de Medicina Social, Universidade do Estado do Rio de Janeiro; 2003.

9. Costa COM, Lima I, Martins Jr. DF, Santos CAST, Araújo FPO, Assis DR. Gravidez na adolescência e co-responsabilidade paterna: trajetória sóciodemográfica e atitudes com a gestação. Ciênc Saúde Coletiva 2005; 10:719-27.

10. Levandowski DC. Paternidade na adolescência: uma breve revisão da literatura internacional. Estud Psicol (Natal) 2001; 6:195-209.

11. Scavone L. Maternidade: transformação na família e nas relações de gênero. Interface Comun Saúde Educ 2001; 5:47-60.

12. Lima CTB, Feliciano KVO, Carvalho MFS, Souza APP, Menabó JBC, Ramos LS, et al. Percepções e práticas de adolescentes grávidas e de familiares em relação à gestação. Rev Bras Saúde Matern Infant 2004; 4:71-83.

13. Peixoto CE. Avós e netos na França e no Brasil: a individualização das transmissões afetivas e materiais. In: Peixoto C, Singly F, Ciccheli V, organizadores. Família e individualização. Rio de Janeiro: Editora FGV; 2000. p. 95-111.

14. Bozon M. Dês rites de passage aux "premières fois": sccio-ethnologie des rites de la jeunesse em France. In: Desdouits AM, Turgeon L, editors. Ethnologies francofhones de l'Amérique et d'ailleurs. 
Québec: Presses de l'Université Laval; 1997. p. 187-96.

15. Galland O. Sociologie de la jeunesse. Paris: Armand Colin; 1997.

16. Aquino EML, Heilborn ML, Knauth D, Bozon M, Almeida MC, Araújo J, et al. Adolescência e reprodução no Brasil: a heterogeneidade dos perfis sociais. Cad Saúde Pública 2003; 19 Suppl 2:S377-88.

17. Sociedade Civil Bem-Estar Familiar no Brasil. Pesquisa nacional sobre demografia e saúde. Rio de Janeiro: Sociedade Civil Bem-estar Familiar no Brasil/Macro Internacional; 1997.

18. World Health Organization. Young people's health a challenge for society. Geneva: World Health Organization; 1986. (WHO Technical Report Series, 731).

19. Aquino EML, Almeida MC, Araújo MJ, Menezes G. Gravidez na adolescência: a heterogeneidade revelada. In: Heilborn ML, Aquino EML, Knauth D, Bozon M, organizadores. O aprendizado da sexualidade: um estudo sobre reprodução e trajetórias sociais de jovens brasileiros. Rio de Janeiro: Garamond; no prelo.

20. Soares S, Carvalho L, Kipnis B. Os jovens de 18 a 25 anos: retrato de uma dívida da política educacional. Rio de Janeiro: Instituto de Pesquisa Econômica Aplicada; 2003. (Texto para Discussão, 954).

21. Sabroza AR, Leal MC, Gama SGN, Costa JV. Algumas repercussões emocionais negativas da gravidez em adolescentes no Município do Rio de Janeiro (1999-2001). Cad Saúde Pública 2004; 20 Suppl 1:S130-7.
22. Cabral CS. Contracepção e gravidez na adolescência na perspectiva de jovens pais de uma comunidade favelada do Rio de Janeiro. Cad Saúde Pública 2003; 19 Suppl 2:S283-92.

23. Heilborn ML. O traçado da vida: gênero e idade em dois bairros populares do Rio de Janeiro. In: Madeira F, organizador. Quem mandou nascer mulher? Estudos sobre crianças e adolescentes pobres no Brasil. Rio de Janeiro: Editora Record/ Rosa dos Tempos; 1997. p. 291-342.

24. Dias AB. Parentalidade juvenil e relações familiares em Salvador, BA [Tese de Doutorado]. Rio de Janeiro: Instituto de Filosofia e Ciências Humanas, Universidade do Estado do Rio de Janeiro; 2005.

25. Goldani AM. Retratos de família em tempos de crise. Revista Estudos Feministas 1994; número especial:303-35.

26. Instituto Brasileiro de Geografia e Estatística. Censo demográfico 2000. Famílias e domicílios: resultados da amostra. Rio de Janeiro: Instituto Brasileiro de Geografia e Estatística; 2003.

27. Luker K. Dubious conceptions. The politics of teenage pregnancy. Cambridge: Harvard University Press; 1996.

28. Fonseca JLCL. Paternidade adolescente: da investigação à intervenção. In: Arilha M, Ridenti SGU, Medrado B, organizadores. Homens e masculinidades: outras palavras. São Paulo: ECOS/Editora 34; 1998. p. 185-214.

29. Peixoto CE. Aposentadoria: retorno ao trabalho e solidariedade familiar. In: Peixoto CL, organizador. Família e envelhecimento. Rio de Janeiro: Editora FGV; 2004. p. 57-84.

Recebido em 16/Set/2005

Versão final reapresentada em 04/Jan/2006 Aprovado em 05/Jan/2006 